\title{
Safety and efficacy of tramadol hydrochloride on treatment of premature ejaculation
}

\author{
Bayoumy I Eassa ${ }^{1}$ and Mohamed A El-Shazly ${ }^{2}$
}

Premature ejaculation (PE) is the most common sexual disorder. It affects $20 \%-30 \%$ of adult men; the aetiology of this condition has not yet been elucidated. The aim of this study is to evaluate the efficacy, safety, tolerability, undesirable effects and improved satisfaction with sexual intercourse with tramadol hydrochloride at different dosages for the treatment of PE. A total of 300 patients who presented with lifelong (primary) PE were included in this study. The study was performed for $\mathbf{2 8}$ weeks, in which placebo (starch tablet) was given for 4 weeks, and active ingredient (tramadol hydrochloride) was administered at different therapeutic dosages for 24 weeks. Patients were divided into three equal groups, each consisting of 100 patients. The first group (A) was given tramadol hydrochloride capsule $25 \mathrm{mg}$. The second group (B) was given tramadol hydrochloride capsule $50 \mathrm{mg}$. The third group (C) was given tramadol hydrochloride capsule $100 \mathrm{mg}$. All of the 300 participants included completed the study voluntarily. The age of the patients varied from 25 to 50 years. After the treatment period, the recorded data were collected for each group and analysed. The results showed a highly significant increase in the mean intravaginal ejaculatory latency time (IELT) in all groups compared to baseline data $(P<0.0001)$. We concluded that using tramadol hydrochloride at different doses on demand for the treatment of PE is effective, safe and tolerable, with minimal undesirable effects, and approval for this indication should be sought.

Asian Journal of Andrology (2013) 15, 138-142; doi:10.1038/aja.2012.96; published online 29 October 2012

Keywords: early ejaculation; erectile dysfunction; intravaginal ejaculation latency time; premature climax; premature ejaculation; PE; rapid ejaculation; tramadol

\section{INTRODUCTION}

Ejaculatory dysfunction is a common and distressing cause of male sexual difficulties. It also represents a significant cause of male factor subfertility, posing distinct reproductive challenges for couples attempting to conceive. Ejaculatory dysfunction can be classified along a spectrum ranging from premature ejaculation $(\mathrm{PE})$, retarded or delayed ejaculation (DE), to complete anejaculation (AE), along with retrograde ejaculation (RE). ${ }^{1}$

$\mathrm{PE}$ is the most common male sexual dysfunction, affecting approximately $20 \%-30 \%$ of the male population at any given time. ${ }^{2}$

Masters and Johnson ${ }^{3}$ first suggested the concept that first intercourse experiences that were rushed and associated with nervousness at the time of inexperienced sex led to PE.

The medical literature contains several definitions of PE. The lack of agreement on what constitutes PE has hampered basic and clinical research into the aetiology and management of this condition. Quantitative measures of intercourse, such as the intravaginal ejaculatory latency time (IELT), the number of thrusts between penetration and ejaculation, the extent of partner sexual satisfaction, and the patient's assessment of his voluntary control over ejaculation, have been described. Each of the four criteria above has been operationalized, although not always with consistency. ${ }^{4}$

The International Society of Sexual Medicine (ISSM) recently published an evidence-based definition of lifelong (primary) PE as a male sexual dysfunction characterized by ejaculation that always or nearly always occurs prior to or within approximately $1 \mathrm{~min}$ of vaginal penetration, the inability to delay ejaculation on all or nearly all vaginal penetrations, and negative personal consequences, such as distress, bother, frustration and/or the avoidance of sexual intimacy. ${ }^{5}$

In 1994, the concept of IELT was introduced. ${ }^{6}$ IELT has been defined as the length of time between vaginal entry (IELT), anal (anal ejaculatory latency time) or oral penetration (oral ejaculatory latency time), or the initiation of masturbation (masturbatory ejaculatory latency time) and ejaculation. ${ }^{7}$ IELT forms the basis of most current clinical studies on PE. ${ }^{8}$

Based on Dutch data, ${ }^{9}$ the baseline IELT defining ejaculation that occurred prematurely was estimated at less than $1 \mathrm{~min}$. Some publications stated that any ejaculation occurring within $1,2,3$, or even 7 min of penetration is considered premature; others specify the number of penile thrusts, considering $8-15$ thrusts as a criterion for PE. Still others consider partner satisfaction, suggesting that a man experiences $\mathrm{PE}$ if he is unable to delay his ejaculation until his partner is sexually satisfied in at least $50 \%$ of their coital connections. ${ }^{10}$

Anteportal ejaculation is the term for men who ejaculate prior to vaginal penetration and is considered the most severe form of PE. Such men/couples typically present when they are having difficulty conceiving children. It is estimated that $5 \%$ of lifelong PE men suffer from anteportal PE. ${ }^{11}$

\footnotetext{
${ }^{1}$ Department of Dermatology, Venereology and Andrology, Al-Azhar University, Cairo 11884, Egypt and 2Department of Urology, Menoufiya University, Cairo 32511, Egypt Correspondence: Dr Bl Eassa (bayeassa@yahoo.com)
} 
PE has been classified as either primary (lifelong), which begins when a male first becomes sexually active, or secondary (acquired), meaning that a male previously had an acceptable level of ejaculatory control and developed the condition later in life, ${ }^{12}$ and it has been associated with chronic prostatitis and specific endocrinopathies, including diabetes mellitus and hyperthyroidism. ${ }^{13}$ In these instances, $\mathrm{PE}$ is usually reversed when the underlying disorder is treated. ${ }^{14}$

The second international consultation on erectile and sexual dysfunctions recommends the use of the term early ejaculation rather than PE; however, PE will continue to be used for the near future. ${ }^{15}$

Tramadol hydrochloride was developed in the late 1970 s. ${ }^{16}$ It possesses weak agonist action at the $\mu$-opioid receptor, releases serotonin and inhibits the reuptake of norepinephrine. ${ }^{17}$ Its mode of action is not completely understood. From animal tests, at least two complementary mechanisms appear applicable: the binding of parent and M1 metabolites to $\mu$-opioid receptors (antinociceptive effect), and the inhibition of the reuptake of norepinephrine and serotonin (5-HT), which may account for its effect on delaying ejaculation. ${ }^{18}$

Tramadol undergoes hepatic metabolism via the cytochrome P450 isozyme CYP2D6 and is $\mathrm{O}$ - and $\mathrm{N}$-demethylated to five different metabolites. Of these, M1 (O-desmethyltramadol) is the most significant metabolite, because it has 200 times the $\mu$-affinity of tramadol and has an elimination half-life of $9 \mathrm{~h}$ compared with $6 \mathrm{~h}$ for tramadol. In the $6 \%$ of the population who have slow CYP2D6 activity, there is a slightly reduced analgesic effect. Phase II hepatic metabolism renders the metabolites water soluble, and they are excreted by the kidneys; thus, reduced doses may be used in renal and hepatic impairment. ${ }^{19}$

The objective of this study was to evaluate the efficacy, safety, tolerability, undesirable effects, improved satisfaction with sexual intercourse and control over ejaculation with tramadol hydrochloride at different dosages for the treatment of PE.

\section{PATIENTS AND METHODS}

\section{Subjects}

A total of 300 heterosexual men complaining of lifelong (primary) PE were recruited from the outpatient clinic of Al-Hussein University Hospital, Al-Azhar University, Cairo, Egypt, from January 2009 to December 2011. The study was approved by the local medical ethics committee. The enrolled men aged 25-50 years had been in a stable, monogamous, heterosexual relationship with regular sexual intercourse at least twice per week with a cooperative female partner and had been married for at least 2 years. The study was performed for 28 weeks, during which the placebo was given for 4 weeks, and the active ingredient (tramadol hydrochloride) (Grünenthal $\mathrm{GmbH}$, Aachen, Germany) was administered at different therapeutic dosages for 24 weeks.

\section{Study design}

Patients were randomly divided through a simple (complete) randomisation process into three groups, each consisting of 100 patients, and administered placebo tablets (starch) for 4 weeks before being administered active ingredient (tramadol hydrochloride). The first group (A) was given tramadol hydrochloride capsule $25 \mathrm{mg}$. The second group (B) was given tramadol hydrochloride capsule $50 \mathrm{mg}$. The third group (C) was given tramadol hydrochloride $100 \mathrm{mg}$. All of the patients were instructed to take the drug with a cup of water $2-3 \mathrm{~h}$ before intercourse. All of the patients were asked about their satisfaction and control of ejaculation before and after treatment, in addition to their tolerance to the drug and whether there were any side effects. No specific validated questionnaire was used in this study.

\section{Investigations}

Routine laboratory investigations were performed for all patients and included complete blood count, urine analysis, liver function test, renal profile, lipid profile, blood sugar, hormonal profile (folliclestimulating hormone, luteinizing hormone, testosterone, and prolactin and thyroid profile (thyroid-stimulating hormone, T3 and T4).

\section{Assessment method (IELT)}

The duration of IELT is the time from penetration (vaginal penetration) until ejaculation (release of semen) and was timed on a stopwatch by 'start' (penetration) to 'stop' (ejaculation). Either of the partners was allowed to handle the stopwatch; however, it was requested that the same person remain responsible for every IELT measurement for the duration of the study, and they were asked to be honest in recording the time. They were instructed to calculate and record the exact time after ejaculation.

After explanation of the purpose of the study, all of the patients agreed to participate in the study, and written informed consent was requested from all patients and signed before starting treatment. They were provided with a stopwatch and a sexual events diary, were carefully instructed on how to measure the IELT and were reminded and confirmed during the follow-up visits (every 2 weeks).

\section{Exclusion criteria}

Exclusion criteria included patients with secondary (organic) PE; sexual dysfunction (decreased sexual interest, erectile dysfunction according to the International Index of Erectile Function, painful intercourse, urinary tract infection, or female sexual dysfunction that affected the sexual relationship); current physical illness (e.g., diabetes mellitus, liver diseases, dyslipidaemia, hypertension, heart diseases, renal diseases, thyroid diseases and hormonal disorders); history of a psychiatric or neurological disorder; substance abuse (alcohol or drug); previous pelvic trauma or surgery; spinal cord injury; or currently taking a drug known to affect sexual function, including either topical penile applications or systemic drugs. All male patients had been circumcized at birth and were asked to avoid condom use.

\section{Statistical analysis}

The computer software Stat View 5 (SAS Institute Inc., Cary, NC, USA) was used for data analysis. Paired $t$-test was used for comparison between the mean values. A $P<0.05$ was considered significance.

\section{RESULTS}

All 300 participants included in this study completed the period voluntarily. The age of the patients varied from 25 to 50 years (mean $34.47 \pm 8.16,33.86 \pm 8.31$ and $33.15 \pm 7.24$ years in groups A, B and C, respectively). No changes in hormonal profile were recorded before and after treatment.

At the end of the first 4 weeks (placebo period), recorded data were collected from all patients and analysed by paired $t$-test. The results showed that the mean IELT was $\leqslant 4 \mathrm{~min}$. The mean baseline of IELT before treatment was $2.82 \pm 0.89$ in group A, 2.79 \pm 0.95 in group B, and $2.99 \pm 0.86$ in group C (Table 1).

At the end of the study, i.e., after 24 weeks of treatment with tramadol hydrochloride, the recorded data were collected from each group and analysed. As shown in Table 1, the mean IELT in all groups was significantly different compared to baseline data $(P<0.0001)$. The IELT was $13.17 \pm 1.83 \mathrm{~min}$ (range $8.00-15.00 \mathrm{~min}$ ) in group $A$, $23.43 \pm 1.78 \mathrm{~min}$ (range 18.00-25.00 $\mathrm{min}$ ) in group B and $36.49 \pm 3.25$ (range $29.00-40.00 \mathrm{~min}$ ) in group C (Table 1). All of the patients 
Table 1 Statistical comparison between all groups

\begin{tabular}{lccc}
\hline & $\begin{array}{c}\text { IELT pre-treatment } \\
\text { (placebo) }(\text { min })\end{array}$ & $\begin{array}{c}\text { IELT post- } \\
\text { treatment }(\text { min })\end{array}$ & P value \\
\hline Group A & $2.82 \pm 0.89$ & $13.17 \pm 1.83$ & $<0.0001$ \\
Group B & $2.79 \pm 0.95$ & $23.43 \pm 1.78$ & $<0.0001$ \\
Group C & $2.99 \pm 0.86$ & $36.49 \pm 3.25$ & $<0.0001$ \\
\hline
\end{tabular}

treated with tramadol hydrochloride at different dosages gained satisfactory control over ejaculation compared to baseline data in each group, and the drug was well tolerated (Figure 1).

Regarding undesirable effects, patients in all groups complained of somnolence (light sleeping or insomnia) and pruritus (itching without skin lesions), and the severity and intensity were dose-dependent. However, the patients in groups $\mathrm{B}$ and $\mathrm{C}$ complained of additional undesirable effects, including dizziness ( $18 \%$ and $38 \%$, respectively), light headache (heaviness) (16\% and 30\%, respectively), and dryness of mouth ( $13 \%$ and $28 \%$, respectively). Nausea (20\%) and vomiting (17\%) were only reported in group C (Table 2). All of these undesirable effects usually resolved approximately $10 \mathrm{~h}$ after ingestion of the drug.

Most of the patients $(90 \%(270 / 300))$ treated with tramadol hydrochloride reported an increase in penile rigidity during intercourse throughout the treatment period, and this claim was confirmed by their partners.

\section{DISCUSSION}

Human sexual function includes sexual libido, penile erection, ejaculation and orgasm. Patients with PE can be divided into primary and secondary PE. Primary (lifelong) PE patients are patients who have suffered chronically from the beginning of their sexual lives, and secondary PE patients have suffered from PE after years of normal sexual functioning. ${ }^{20}$

$\mathrm{PE}$ is the most common form of male sexual dysfunction, affecting $30 \%$ of men, and it is defined as an inability to exert voluntary control over the ejaculatory reflex, resulting in rapid orgasm. ${ }^{21}$ Currently, available data suggest that only $1 \%-12 \%$ of males self-reporting PE receive treatment for their dysfunction. ${ }^{2}$ In a recent study conducted in Korea, the self-reported prevalence rate was $27.5 \% .^{22}$

$\mathrm{PE}$, unlike ED, affects men of all ages equally. However, both PE and ED coexist, and PE can often be misdiagnosed as ED in many men.

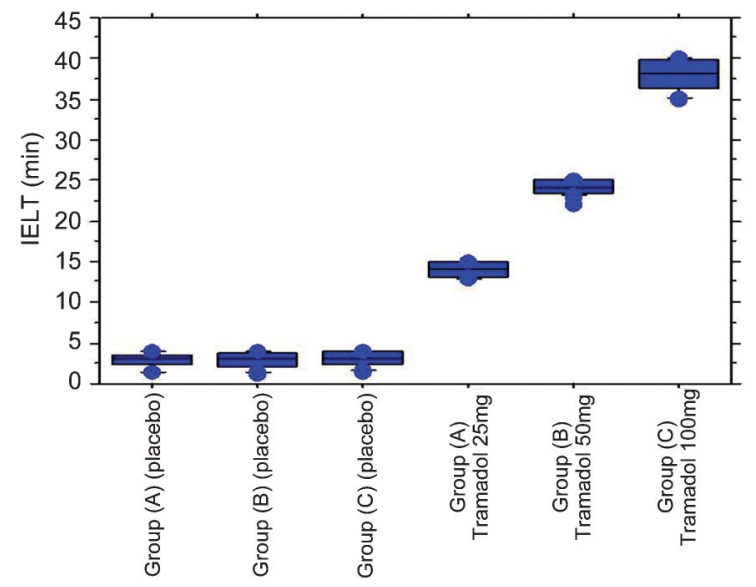

Figure 1 Mean IELT in all groups before and after treatment. IELT, intravaginal ejaculatory latency time.
Table 2 Undesirable side effects in all groups

\begin{tabular}{lccc}
\hline Symptoms & Group A & Group B & Group C \\
\hline Somnolence & $100 \%(100 / 100)$ & $100 \%(100 / 100)$ & $100 \%(100 / 100)$ \\
Pruritus & $100 \%(100 / 100)$ & $100 \%(100 / 100)$ & $100 \%(100 / 100)$ \\
Dizziness & - & $18 \%(18 / 100)$ & $38 \%(38 / 100)$ \\
Headache & - & $16 \%(16 / 100)$ & $30 \%(30 / 100)$ \\
Mouth dryness & - & $13 \%(13 / 100)$ & $28 \%(28 / 1000$ \\
Nausea & - & - & $20 \%(20 / 100)$ \\
Vomiting & - & - & $17 \%(17 / 100)$ \\
\hline
\end{tabular}

This is, in part, due to the lack of knowledge about PE, the absence of performing a careful history, and the nonexistence of diagnostic tools for $\mathrm{PE}^{23}$

The diagnostic criterion for many authors is the time between penetration and ejaculation, and this time is agreed to be $1 \mathrm{~min}^{24}$ Rowland et al. ${ }^{4}$ suggested that an IELT of 2 min or less may serve as an adequately sensitive criterion for defining PE. Other authors concluded that any ejaculation occurring within 1,2, 3, or even 7 min of penetration should be considered premature, ${ }^{10}$ but none of the definitions offer any supportive rationale for their proposed cut-off time. ${ }^{8}$ Waldinger et al. ${ }^{25}$ published multinational reports of IELT (The Netherlands, United Kingdom, United States, Spain and Turkey), and they found that the median IELT was 5.4 min (range 0.55$44.1 \mathrm{~min}$ ) and that the distribution of IELT in all five countries was positively skewed.

The exact aetiology of PE is unknown, but it is believed to include neurobiological and/or psychological components and/or penile hypersensitivity. ${ }^{26}$

There are multiple reports in the literature on the use of a variety of drugs in the treatment of PE. These drugs facilitate ejaculation through either a central dopaminergic or anti-serotoninergic mechanism of action. ${ }^{27,28}$

PE has been treated with various modalities, including behavioural therapy ${ }^{3}$, topical anaesthetic creams or sprays, ${ }^{29}$ and off-label use of oral pharmacotherapy, such as phosphodiesterase-5 inhibitors, ${ }^{30}$ selective serotonin reuptake inhibitors (SSRIs) (fluoxetine, citalopram and duloxetine), ${ }^{31}$ and a tricyclic antidepressant (clomipramine) that blocks serotonin, dopamine and norepinephrine transporters. ${ }^{32}$ These modalities are associated with variable rates of success when taken daily, ${ }^{33,34}$ and intracavernosal vasoactive drug injection has also been reported. ${ }^{35}$ In contrast, some reports suggest that these drugs may be effective when received as needed. ${ }^{36,37}$

Other agents, including $\alpha$-adrenoreceptor antagonists (terazosin and alfuzosin) ${ }^{38}$ and an analgesic opioid receptor agonist and noradrenalin reuptake inhibitor (tramadol), have also been investigated for treating PE. ${ }^{39}$ Psychotherapy and behavioural therapy also have a role, although well-designed, controlled trials that use such approaches are lacking. ${ }^{40}$

PE management is dependent upon aetiology. When secondary to $\mathrm{ED}$, aetiology-specific treatment is employed. When PE is lifelong, initial pharmacotherapy (SSRI, topical anaesthesia, or phosphodiesterase- 5 inhibitors) is appropriate. When PE is associated with psychogenic/relationship factors, behavioural therapy is indicated. When $\mathrm{PE}$ is acquired, pharmacotherapy and/or behavioural therapies are preferred $^{2}$. Melnik et al. ${ }^{41}$ concluded that there is weak and inconsistent evidence regarding the effectiveness of psychological interventions for the treatment of PE.

Currently, there is no US Food and Drug Administration (FDA)approved pharmacological therapies for treating PE. ${ }^{42}$ To date, the largest trials of a treatment for $\mathrm{PE}$ have been conducted with dapoxetine, a 
short-acting SSRI that is the only oral agent approved for the treatment of PE in several European, Asia-Pacific and South American countries. ${ }^{43}$

Tramadol is almost completely absorbed when given orally, and it has an apparent elimination half-life of $6 \mathrm{~h}$ in humans. Its bioavailability of $70 \%$ after a single administration can be entirely attributed to first-pass metabolism. After multiple dosing, the bioavailability increases to almost $100 \%$. Twenty percent of the drug is bound to plasma proteins. Approximately $90 \%$ of the administered dose is recovered in urine either unchanged $(30 \%)$ or as metabolites $(60 \%)$, and the remainder is eliminated in the faeces. ${ }^{44}$

Safarinejad and Hosseini ${ }^{45}$ published a double-blind, placebo-controlled, fixed-dose study indicating that the on-demand use of $50 \mathrm{mg}$ tramadol exerted a significant ejaculation-delaying effect in men with PE. Additionally, Salem $e t a{ }^{42}$ in a single-blind, placebo-controlled study in men with PE, concluded that the on-demand use of $25 \mathrm{mg}$ tramadol showed impressive results in delaying ejaculation. ${ }^{42}$

In an open-label crossover comparative study of daily paroxetine $(20 \mathrm{mg})$ and on-demand tramadol $(50 \mathrm{mg})$ in 35 subjects with lifelong $\mathrm{PE}$, superior IELT fold increases and responses were demonstrated with paroxetine ( 22 fold $v$ s. fivefold for tramadol) after 12 weeks of treatment. ${ }^{39}$

Hellstrom ${ }^{46}$ stated that tramadol for the treatment of PE showed promise, but the data available from small trials need to be corroborated. In addition, long-term studies are warranted to investigate the risk of opioid addiction. Bar-Or et al. ${ }^{47}$ concluded that using the tramadol orally disintegrating tablet on demand is an effective treatment for PE at a small (62 mg) and safe therapeutic dose, and it provides a new option for managing mild to severe $\mathrm{PE}$.

Xiong et al. ${ }^{48}$ found that the treatment of PE with tramadol hydrochloride with behavioural modification showed positive effects in prolonging IELT and improving partners' intercourse satisfaction. More multicentre and double-blind studies are required to evaluate its efficacy and safety as a routine therapy for PE. Kaynar et al. ${ }^{49}$ also stated that the use of low-dose tramadol on demand is effective for lifelong PE.

In our study, we concluded that the use of tramadol hydrochloride at 25,50 or $100 \mathrm{mg}, 2-3 \mathrm{~h}$ on demand before sexual activity showed a highly significant delay in ejaculation and a 10 - to 20 -fold increase in IELT compared to mean baseline data. At the same time, the drug was well accepted and tolerated regarding its side effects, especially at low dosage $(25$ and $50 \mathrm{mg}$ ). This result is in agreement with previous studies. $^{39,42,45-49}$

Tramadol has long been considered to have a low abuse potential. Although it is an opioid agonist, it has not been classified as a scheduled substance. According to the US FDA, the rate of addiction was 1 in 100000 during the last 18 -month period of surveillance. ${ }^{50}$ Because the M1 metabolite is the principal agonist for $\mu$-opioid receptors, the delayed agonist activity reduces dependence liability. The noradrenalin reuptake effects may also play a role in reducing dependence. ${ }^{51}$

A trial in a chronic pain population of 11352 enrolled subjects, 8139 of whom completed the trial and $68.2 \%$ of whom were female, identified that the rate of abuse with tramadol $(2.7 \%)$ was not significantly greater than nonsteroidal anti-inflammatory drugs $(2.5 \%)$ and less than oxycodone $(4.9 \%) .^{52}$

Regarding addiction to tramadol hydrochloride, we believe that the use of this drug on demand is safe and tolerable, especially within the therapeutic dose range from 50-400 mg daily (mentioned in the package insert). According to the US FDA, the rate of addiction was low and mostly reported in patients with a prior history of substance abuse. ${ }^{49,50}$

Although the mechanism by which tramadol delays ejaculation has not been elucidated, numerous laboratory studies have shown that tramadol acts as a mild $\mu$-opioid agonist, ${ }^{23} \mathrm{~N}$-methyl-D-aspartate receptor antagonist. ${ }^{53}$ 5-hydroxytryptamine type $2 \mathrm{C}$ receptor antagonist, ${ }^{54}$ - -nicotinic acetylcholine receptor antagonist, ${ }^{55} \mathrm{M} 1$ and M3 muscarinic acetylcholine receptor antagonist, ${ }^{56}$ and a serotonin and norepinephrine modulator. ${ }^{23}$ It is possible that one or a combination of these effects leads to a delay in ejaculation.

Safarinejad and Hosseini ${ }^{45}$ hypothesized that tramadol affects PE through a multimodal mechanism, including inhibiting the neuronal reuptake of serotonin, inhibiting the neuronal reuptake of noradrenaline, enhancing serotonin efflux, antinociceptive effects and inhibiting spinal somatosensory evoked potentials; thus, it has anaesthetic-type effects on peripheral sensory nerves.

Most of the patients included in this study reported that the drug reduced penile sensitivity, especially the gland penis, and this result is in agreement with Safarinejad and Hosseini, who mentioned the anaesthetic-type effect on peripheral sensory nerves, ${ }^{45}$ and in disagreement with Paick et al., ${ }^{57}$ who failed to identify any penile hypersensitivity factors in patients with PE.

Tramadol has been used off-label and empirically since 2000 for the treatment of PE, because of its acceptable safety profile and because patients taking tramadol for analgesia reported delayed ejaculation. ${ }^{48}$ As a result of its short half-life, tramadol can be used in an on-demand dosing protocol. ${ }^{58}$

The inability to control and defer ejaculation until the female partner is sexually satisfied in at least $50 \%$ of intercourse attempts was proposed as a definition of PE by Masters and Johnson. ${ }^{3}$ An inherent problem exists in defining a man as dysfunctional based on the sexual response of his partner, as only $30 \%$ of women achieve orgasm during sexual intercourse, regardless of the extent of their partner's ejaculatory control and latency. ${ }^{2}$

The undesirable effects reported from the patients in this study were minimal, temporary and not serious compared to other medications used for the treatment of PE, especially SSRIs, in which delayed ejaculation occurs at the expense of a decrease in libido and a moderate decrease in penile rigidity. ${ }^{59}$ In our study, most of the patients reported an increase in penile rigidity during intercourse throughout the treatment period.

Zin et al.$^{60}$ stated that the most important priorities that need to be addressed in the research of PE are the lack of a standard animal model and adequately powered aetiological studies enrolling both PE patients and unafflicted control males. There remains a long way to go in terms of future research.

The ideal treatment for PE should meet the following criteria: ondemand treatment with quick onset of action so as not to interfere with sexual spontaneity, high rates of efficacy after early doses and minimal sexual and other adverse effects. ${ }^{61}$ We met the above criteria in our study, with minimal adverse effects and no reduction in sexual activities.

\section{CONCLUSIONS}

We concluded that using tramadol hydrochloride on demand at small dosages (25 and $50 \mathrm{mg}$ ) for the treatment of PE is acceptable for managing PE because it is effective, safe, and tolerable, with nonserious side effects, and approval for this indication should be sought.

\section{AUTHOR CONTRIBUTIONS}

BIE contributed to conception, design, acquisition, analysis and interpretation of data, drafting the manuscript, revising it critically for important intellectual content, and giving final approval of the version to be published. MAE contributed to conception, interpretation of data, and final approval of the version to be published. 


\section{COMPETING FINANCIAL INTERESTS}

All authors declare that there are no competing financial interests.

1 Barazani Y, Stahl JP, Nagler HM , Stember DS. Management of ejaculatory disorders in infertile men. Asian J Androl 2012; 12: 1-5.

2 Rosen R, Porst H, Montorsi F. The premature ejaculation prevalence and attitudes (PEPA) survey: a multi-national survey [abstract]. Proceedings of the 11th World Congress of the International Society of Sexual and Impotence Research 2004;1721 October 2004.

3 Masters WH, Johnson VE. Human Sexual Inadequacy. Boston: Little, Brown and company; 1970. p29-115.

4 Rowland DL, Cooper SE, Schneider M. Defining early ejaculation for experimental and clinical investigations. Arch Sex Behav 2001; 30: 235.

5 Althof SE, Abdo CH, Dean J, Hackett G, McCabe M et al. International Society for Sexual Medicine's guidelines for the diagnosis and treatment of premature ejaculation. J Sex Med 2010; 7: 2947-69.

6 Waldinger MD, Hengeveld MW, Zwinderman AH. Paroxetine treatment of premature ejaculation: A double-blind, randomized, placebo-controlled study. Am J Psychiatry 1994; 151: 1377-9.

7 Waldinger MD. Four measures of investigating ejaculatory performance. J Sex Med 2007; 4: 520.

8 Schover LR, Friedman JM, Weiler SJ, Heiman JR. LoPiccolo J. Multiaxial problemoriented system for sexual dysfunctions. Arch Gen Psychiat 1982; 39: 614.

9 Olivier B. An empirical operationalization study of DSM-IV diagnostic criteria for premature ejaculation. Int J Psychiatry Clin Pract 1998; 2: 287-93.

10 Jannini EA, Lenzi A. Ejaculatory disorders: epidemiology and current approaches to definition, classification and subtyping. World J Urol 2005; 23: 68-75.

11 McMahon CG. Long term results of treatment of premature ejaculation with selective serotonin re-uptake inhibitors. Int J Impot Res 2002; 14: S19.

12 Godpodinoff ML. Premature ejaculation: clinical subgroups and etiology. J Sex Marital Ther 1989; 15: 130-4.

13 El-Nashaar A, Shamloul R. Antibiotic treatment can delay ejaculation in patients with premature ejaculation and chronic bacterial prostatitis. J Sex Med 2007; 4: 491-6.

14 Cihan A, Demir O, Demir T, Aslan G, Comlekci A et al. The relationship between premature ejaculation and hyperthyroidism. J Urol 2009; 181: 1273-80.

15 Goldstein I. Premature to early ejaculation: a sampling of manuscripts regarding the most common male sexual dysfunction published in the IJIR. J Sex Med 2003; 15: 307-8.

16 Flick K, Frankus E. 1-(m-Substituted Phenyl)-2-Aminomethyl Cyclohexanols, issued 28 March 1972

17 Gobbi M, Moia M, Pirona L, Ceglia I, Reyes-Parada M et al. P-Methylthioamphetamine and 1-(m-chlorophenyl) piperazine, two non-neurotoxic 5-HT releasers in vivo, differ from neurotoxic amphetamine derivatives in their mode of action at 5-HT nerve endings in vitro. J Neurochem 2002; 82: 1435-43.

18 Frink MC, Hennies HH, Englberger W, Haurand M, Wilffert B. Influence of tramadol on neurotransmitter systems of the rat brain. Arzneimittelforschung 1996; 46: 102936.

19 Dayer P, Desmeules J, Collart L. Pharmacology of tramadol. Drugs 1997; 53: Suppl 2: 18-24.

20 Choi1 HK, Xin ZC, Choi YD, Lee WH, Mah SY et al. Safety and efficacy study with various doses of SS-cream in patients with premature ejaculation in a double-blind, randomized, placebo controlled clinical study. Int J Impot Res 1999; 11: 261-4

21 Xin ZC, Chung WS, Choi YD, Seong DH, Choi YJ et al. Penile sensitivity in patients with primary premature ejaculation. J Urol 1996; 156: 979-81.

22 Park HJ, Park JK, Park K, Lee SW, Kim SW et al. Prevalence of premature ejaculation in young and middle-aged men in Korea: a multicenter internet-based survey from the Korean Andrological Society. Asian J Androl 2010; 12: 880-9.

23 Montague DK, Jarow J, Broderick GA, Dmochowski RR, Heaton JP et al. AUA Erectile Dysfunction Guideline Update Panel. AUA guideline on the pharmacologic management of premature ejaculation. J Urol 2004; 172: 290-4.

24 Kaplan HS. The New Sex Therapy: Active Treatment of Sexual Dysfunctions. NewYork: Brunner/Mazel; 1974

25 Waldinger M, Quinn P, Dilleen M, Mundayat R, Schweitzer D et al. A multinational population survey of intravaginal ejaculation latency time. J Sex Med 2005; 2: 292-7.

26 Morales A, Barada J, Wyllie MG. A review of the current status of topical treatments for premature ejaculation. BJU Int 2007; 100: 493-501.

27 Ashton K, Hamer R, Rosen R. Serotonin reuptake inhibitor-induced sexual dysfunction and its treatment: a large-scale retrospective study of 596 psychiatric outpatients. J Sex Marital Ther 1997; 23: 165.

28 Gitlin MJ. Treatment of sexual side effects with dopaminergic agents. J Clin Psychiatry 1995; 56: 124.

29 Palmer NR, Stuckey BG. Premature ejaculation: a clinical update. Med J Aust 2008; 188: $662-6$.

30 Shindel A, Nelson C, Brandes S. Urologist practice patterns in the management of premature ejaculation: a nationwide survey. J Sex Med 2008; 5: 199-205.
31 Bettocchi C, Verze P, Palumbo F, Arcaniolo D, Mirone V. Ejaculatory disorders: pathophysiology and management. Nat Clin Pract Urol 2008; 5: 93-103.

32 Althof SE, Levine SB, Corty EW, Risen CB, Stern EB et al. A double-blind crossover trial of clomipramine for rapid ejaculation in 15 couples. J Clin Psychiatry 1995; 56: 402-7.

33 Kim SC, Seo KK. Efficacy and safety of fluoxetine, sertraline and clomipramine in patients with premature ejaculation: a double blind placebo controlled study. J Urol 1998; 159: 425-7.

34 Girgis SM, EL Haggar S, EL Hermouzy S. A double blind trial of clomipramine in premature ejaculation. Andrologia 1982; 14: 364-8.

35 Fein RL. Intracavernous medication for treatment of premature ejaculation. Urology 1990; 35: 301-3.

36 Haensel SM, Rowland DL, Kallan KT. Clomipramine and sexual function in men with premature ejaculation and controls. J Urol 1996; 156: 1310-5.

$37 \mathrm{Kim} \mathrm{SW}$, Paick JS. Short-term analysis of the effects of as needed use of sertraline at 5 pm for the treatment of premature ejaculation. Urology 1999; 54: 544-7.

38 Basar MM, Yilmaz E, Ferhat M, Basar H, Batislam E. Terazosin in the treatment of premature ejaculation: a short-term follow-up. Int Urol Nephrol 2005; 37: 773-7.

39 Alghobary M, El-Bayoumy Y, Mostafa Y, Mahmoud EH, Amr M. Evaluation of tramadol on demand vs. daily paroxetine as a long-term treatment of lifelong premature ejaculation. J Sex Med 2010; 7: 2860-7.

40 Gurkan L, Oommen M, Hellstrom WJ. Premature ejaculation: current and future treatments. Asian J Androl 2008; 10: 102-9.

41 Melnik T, Althof S, Atallah AN, Puga ME, Glina S et al. Psychosocial interventions for premature ejaculation. Cochrane Database Syst Rev 2011; 10: CD008195.

42 Salem EA, Wilson SK, Bissada NK, Delk II JR, Hellstrom WJ et al. Tramadol HCL has promise in on-demand use to treat premature ejaculation. J Sex Med 2008; 5: 18893.

43 McMahon C, Kim SW, Park NC, Chang CP, Rivas D et al. Dapoxetine 3003 Study Investigators. Treatment of premature ejaculation in the Asia-Pacific region: results from a phase III double-blind, parallel-group study of dapoxetine. J Sex Med 2010; 7: 256-68.

44 Lintz W, Erlacin S, Frankus E, Uragg H. [Biotransformation of tramadol in man and animal (author's transI)]. Arzneimittelforschung 1981; 31: 1932-43. German.

45 Safarinejad MR, Hosseini SY. Safety and efficacy of tramadol in the treatment of premature ejaculation. J Clin Psychopharmacol 2006; 26: 27-31.

46 Hellstrom WJ. Update on treatments for premature ejaculation. Int J Clin Pract 2011; 65: 16-26

47 Bar-Or D, Salottolo KM, Orlando A, Winkler JV. A randomized double-blind, placebocontrolled multicenter study to evaluate the efficacy and safety of two doses of the tramadol orally disintegrating tablet for the treatment of premature ejaculation within less than 2 minutes. Eur Urol 2012; 61: 736-43.

48 Xiong GG, Wu FH, Chen SH, Yao WL. Safety and efficacy of tramadol hydrochloride with behavioral modification in the treatment of premature ejaculation. Zhonghua Nan Ke Xue. 2011; 17: 538-41.

49 Kaynar M, Kilic O, Yurdakul T. On-demand tramadol hydrochloride use in premature ejaculation treatment. Urology 2012; 79: 145-9.

50 Cicero TJ, Adams EH, Geller A, Inciardi JA, Munoz A et al. A post marketing surveillance program to monitor Ultram (tramadol hydrochloride) abuse in the United States. Drug Alcohol Depend 1999; 57: 7-22.

51 Näslund S, Dahlqvist R. Treatment with tramadol can give rise to dependence and abuse (Article in Swedish). Lakartidningen 2003; 100: 712-4.

52 Adams EH, Breiner S, Cicero TJ, Geller A, Inciardi JA et al. A comparison of the abuse liability of tramadol, NSAIDs, and hydrocodone in patients with chronic pain. $J$ Pain Symptom Manage 2006; 31: 465-76.

53 Hara K, Minami K, Sata T. The effects of tramadol and its metabolite on glycine, gamma-amino butyric acid $\mathrm{A}$, and $\mathrm{N}$-methyl-D-aspartate receptors expressed in Xenopus oocytes. Anesth Analg 2005; 100: 1400-5.

54 Ogata J, Minami K, Uezono Y, Okamoto T, Shiraishi M et al. The inhibitory effects of tramadol on 5-hydroxytryptamine type $2 \mathrm{C}$ receptors expressed in Xenopus oocytes. Anesth Analg 2004; 98: 1401-6.

55 Shiraishi M, Minami K, Uezono Y, Yanagihara N, Shigematsu A et al. Inhibitory effects of tramadol on nicotinic acetylcholine receptors in adrenal chromaffin cells and in Xenopus oocytes expressing alpha 7 receptors. Br J Pharmacol 2002; 136: 207-16.

56 Shiga Y, Minami K, Shiraishi M, Uezono Y, Murasaki $O$ et al. The inhibitory effects of tramadol on muscarinic receptor-induced responses in Xenopus oocytes expressing cloned M (3) receptors. Anesth Analg 2002; 95: 1269-73.

57 Paick J-S, Jeong H, Park M-S. Penile sensitivity in men with premature ejaculation. Int J Impot Res 1998; 10: 247-50.

58 Grond S, Sablotzki A. Clinical pharmacology of tramadol. Clin Pharmacokinetic 2004; 43: 879-923.

59 Sadeghi-Nejad H, Watson R. Premature ejaculation, Current medical treatment and new directions. J Sex Med 2008; 5: 1037-50.

60 Xin ZC, Zhu YC, Yuan YM, Cui WS, Jin Z et al. Current therapeutic strategies for premature ejaculation and future perspectives. Asian J Androl 2011; 13: 550-7.

61 Mulhall JP. Current and future pharmacotherapeutic strategies in treatment of premature ejaculation. Urology 2006; 67: 9-16. 